\title{
Individual and Obstetric Risk Factors of Preeclampsia among Singleton Pregnancy in Hospitals of Southern Ethiopia
}

\author{
Kassahun Fikadu Tessema $\mathbb{D}^{1},{ }^{1}$ Feleke Gebremeskel, ${ }^{2}$ Firdawek Getahun, ${ }^{2}$ Nega Chufamo, ${ }^{3}$ \\ and Direslgne Misker ${ }^{2}$ \\ ${ }^{1}$ Department of Midwifery, Arbaminch University, Arab Minch, Ethiopia \\ ${ }^{2}$ School of Public Health, Arbaminch University, Arab Minch, Ethiopia \\ ${ }^{3}$ Department of Obstetrics and Gynecology, Arbaminch University, Arab Minch, Ethiopia
}

Correspondence should be addressed to Kassahun Fikadu Tessema; kasfika@gmail.com

Received 5 May 2020; Revised 9 November 2020; Accepted 8 January 2021; Published 20 January 2021

Academic Editor: Tomohiro Katsuya

Copyright (c) 2021 Kassahun Fikadu Tessema et al. This is an open access article distributed under the Creative Commons Attribution License, which permits unrestricted use, distribution, and reproduction in any medium, provided the original work is properly cited.

\begin{abstract}
Background. Preeclampsia is the second most common problem that causes maternal morbidity and complication in low-income countries. In contrast to death due to other direct causes, preeclampsia-related death is appeared to be connected with multiple factors; yet, factors have paucity and are limited. Considering the clinical significance, this study aimed to identify that individual and obstetric factors of preeclampsia can be an input for disease identification involving clinicians in southern Ethiopia. Methods. A case-control study was conducted among mothers with a singleton pregnancy who attended perinatal care in all six public hospitals in the provinces around the Omo stream. A sample size of 487 women with a singleton pregnancy (163 cases and 326 controls) was involved in the study. All cases were enrolled, while controls were selected consecutively using a random sampling technique. Data were gathered using a structured questionnaire and data extraction sheet. Descriptive data were presented using percentages and numbers. Multivariable logistic regression analysis was carried out to identify factors at a $p$ value of less than 0.05 . Results. There was a statistically significant association between the family history of hypertension $(\mathrm{AOR}=2.42,95 \% \mathrm{CI}$ : $1.16-5.05)$, no pregnancy interval ( $\mathrm{AOR}=1.62$; $95 \% \mathrm{CI}: 1.03-2.55)$, and normal body mass index ( $\mathrm{AOR}=0.42,95 \% \mathrm{CI}: 0.21-0.87$ ) and the occurrence of preeclampsia. Conclusion. Primary relatives with a history of chronic hypertension and no pregnancy interval were identified as risk factors of preeclampsia, while having a normal body mass index was found to be a protective factor of preeclampsia occurrence. To improve early detection and timely management of preeclampsia, the clinician should give attention to women who have no previous childbirth and whose close relatives had a history of chronic hypertension, as well as working on the protective factor is recommended.
\end{abstract}

\section{Background}

Both in the high income and low-resource setting countries across the globe, hypertensive disorders of pregnancy have persisted as a global burden that attributes to maternal and perinatal morbidity and mortality [1]. Hypertensive disorders of pregnancy are appeared to be one of the top five causes of maternal morbidity and mortality [2]. According to the recent World Health Organisation (WHO) report, more than $9 \%$ of maternal death in Africa was due to hypertensive disorders of pregnancy $[1,3]$. About $9 \%$ of maternal death in Ghana was also because of gestational hypertension. A five-year retrospective study conducted in Shoa district revealed that approximately $12 \%$ of maternal death happened because of hypertensive disorder of pregnancy, while about $17 \%$ of maternal death in Ethiopia was due to pregnancy-induced hypertension $[4,5]$.

The incidence of preeclampsia in developing countries is estimated to be seven times higher than the developed world [6]. The global incidence of preeclampsia is estimated to be from $5 \%$ to $14 \%$, while in developing countries, the incidence is increased by $4 \%$ [7]. The overall prevalence of preeclampsia across studies varies from $4 \%$ to $23 \%$ [8]. In the USA, preeclampsia affects $4 \%$ of pregnancies [9], in Kenya 
(6.1\%) [10], Nigeria (2\%-14\%) [6], and Ethiopia (4.74\%) [11]. Regarding the severe form of the disease, severe preeclampsia accounts $25 \%$ of all preeclampsia cases [7].

The severe form of preeclampsia results in maternal system dysfunction, and its consequences involve maternal and fetal morbidity and death. Worldwide, nearly $12 \%$ of direct maternal death is contributed by the complications of preeclampsia [12]. In Ethiopia, preeclampsia contributes $10 \%$ of all maternal mortality and $16 \%$ of direct maternal death [13]. Unlike maternal death due to haemorrhage/ obstructed labour or sepsis, maternal death due to preeclampsia has been increasing and remains a major public health problem. Nevertheless, in the majority of cases, maternal death due to preeclampsia is preventable using an effective and timely provision of care [14].

Giving due attention to this public health problem may contribute to the overall effort of reducing maternal mortality in Ethiopia. Ethiopia has identified preeclampsia as one of the contributions of maternal death, and the government has been working on quality improvement aspects of the maternal health services. The intervention involves the job training for clinicians, which aimed to enable them to detect and manage preeclampsia using magnesium sulphate, as well as supportive supervision and mentoring and availability of supplies to health facilities with the support of health development partners [15]. However, the unpredictable nature of the disease and limited evidence on factors of preeclampsia made the effort tiresome. Considering the benefit of documentation on factors of preeclampsia in reducing the overall incidence of preeclampsia, this study was aimed to determine individual and obstetric factors of preeclampsia in hospitals of southern Ethiopia.

\section{Methods}

2.1. Study Area and Period. This case-control study design was conducted in six district public health hospitals in southern Ethiopia. All the districts are located along with the Omo river stream. In the Gamo, Goffa, Derashe, and Konso districts are in the upstream, while South Omo district is regarded as the low stream. The study was carried out at the hospital of each district, where each has one government owing hospital during the study period between February and August 2018. The hospitals included in this study were Arbaminch General Hospital, Konso District Hospital, Sawla District Hospital, Chencha District Hospital, Jinka General Hospital, and Gidole District Hospital. Cases were pregnant women with a new onset of elevated diastolic blood pressure of $90 \mathrm{mmHg}$ and/or systolic blood pressure of $140 \mathrm{mmHg}$ on two consecutive records of four-six hours apart or highly elevated blood pressure (diastolic blood pressure $\geq 110 \mathrm{mmHg}$ and/or a systolic blood pressure $\geq 160 \mathrm{mmHg}$ ) of a single occurrence, plus protein in the urine estimated to be $300 \mathrm{gm}$ per day or urine dipstick record of $>1+$ after 20 weeks of gestation, and controls were pregnant women not diagnosed with preeclampsia $[1,16]$. Gestational age was calculated referring to the pregnant women's recall of the last normal menstrual period (LMP). A documented early ultrasound record was used to compute the gestational age for those who failed to remember the exact date of their last menstrual period. To prevent misclassification, pregnant women who did not remember LMP and had no ultrasound record were excluded.

2.2. Sample Size Calculation and Sampling Technique. Epi-Info version 7.2 was used to compute the estimated sample size using double population proportion formula by assuming antenatal counselling as a factor for with lowest odds ratio of 1.8 and $40.2 \%$ cases among controls from previously published research studies [17]. In addition, 95\% confidence interval, $5 \%$ marginal error, and $80 \%$ power were considered. The calculated sample size was 443 , and after adding a $10 \%$ nonresponse rate, the final sample size was 487 (163 cases and 326 controls).

All the six hospitals were selected purposely because they are public health hospitals that cover the majority of the maternal health service utilization in the catchment. Consecutively appearing cases for antenatal and delivery services at these hospitals during the study period were enrolled. The selection of cases was carried out after the duty physician (general practitioner (GP) or gynaecologist) had the diagnosis preeclampsia. Thus, for each selected case, two consecutively appearing pregnant women who had fulfilled the criteria for controls were enrolled. This ensured a case and control ratio of $1: 2$. This was made using the delivery register as the sampling frame list. The sampling frame was updated based on the antenatal attendees and deliveries that take place in the study hospitals. The sample size distributed between the six hospitals was proportional to their antenatal and delivery caseload. Participants were informed to sign a consent form, and for those subjects below 18 years, parent/ guardian was required to sign an assent form on a separate sheet.

2.3. Data Collection Instrument and Personnel. Data were gathered using a structured and pretested data questionnaire by face-to-face interview. To ensure consistency, the English version data collection tool was translated into Amharic (the national working language), and it was translated back to English by using language experts. The questionnaire consists of three parts, such as sociodemographic factors, personnel, and obstetric-related variables. It was prepared by referring to different works of literature [18-22]. Twelve Amharic speaking diploma and degree level midwives were recruited as data collectors. Six medical doctors supervised the data collection process in coordination with the principal investigator. Supervisors had a daily check on the completeness, consistency, and clarity of the data before the start of data collection in the following day. Along with the investigator, the supervisor had informed data collectors to review the questionnaire for completeness and any missing variables once before the discharge of the participant. To assure data quality, data collectors and supervisors were taken two days training on reviewing technique, the objective of the study, and ethical aspects involving informed consent and confidentiality issues. Moreover, the pretest of the data collection was carried out in area outside of the 
study area (in Wolaita Sodo Comprehensive and Teaching Specialized Hospital) on 10\% (50) of samples.

2.4. Measurement. To avoid the white coat effect and transient elevation of blood pressure because of anxiety and exhaustion, we allowed the participant to take rest for five to ten minutes before the start of blood pressure. To ensure the functionality of the cuff, data collectors checked on a daily basis. A mercury sphygmomanometer was used, and the apparatus covers the upper two-thirds arm. At the antenatal clinic, the record of blood pressure was performed while the women were seated in the upright position. The record of blood pressure for women in the delivery unit left lateral position was used. At both service delivery units, right brachial pressure was taken. During the procedure, the cuff was inflated at a rate of $2-3 \mathrm{mmHg}$ per second. Systolic blood pressure (SBP) was noted as the first Korotkoff sound has been heard, and diastolic blood pressure (DBP) was obtained when the fourth Korotkoff sound was heard. Upon detection of abnormal or unsatisfactory measurements, the measurement was repeated at least four hours apart to confirm the diagnosis. However, the final confirmation was done by the duty physician. Those pregnant women with the diagnosis of severe preeclampsia (blood pressure of 160/ $110 \mathrm{mmHg}$ at any record) were sent for immediate medical management and reevaluation. Information about proteinuria and other relevant data were accessed from maternity charts.

2.5. Data Management, Analysis, and Interpretation. After manual checking of the filled questionnaire for completeness, cleaning and data entry was made into EpiInfo version 7.2 statistical software and transferred to Statistical Package for Social Sciences (SPSS) version 26.0 for further analysis. For all variables, data accuracy and missed values were checked with a frequency run, while crosstabulation and the chi-square test were made to compare cases and controls for categorical variables. Frequency (\%) was used to describe categorical variables. Odds ratio (OR) and $95 \%$ confidence intervals were calculated to measure relevant variables in bivariable regression analysis and variables with $p$ value less than or equal to 0.25 , as well as evidence from previously published research outputs and plausibility were considered to fit variables into the final multivariable regression analysis model. The predictive value of the model was assessed using Hosmer-Lemeshow goodness-of-fit test statistics. In multivariable regression analysis, adjusted odds ratio (AOR) and the corresponding 95\% confidence intervals for cases were calculated to see the strength of the association between the outcome and explanatory variables. Finally, independent variables with a $p$ value of less than 0.05 were considered as a statistically significant factor of preeclampsia.

\section{Results}

3.1. Sociodemographic Characteristics of the Study Participants. From a total of 487 (163 case and 326 controls) participants, 7 cases had withdrawn from the interview. A total of $480(156(32.0 \%)$ cases and $326(67.9 \%)$ controls) who came for perinatal care in Omo district hospitals participated and completed the interview; this gives a response rate of $98.56 \%$ for both cases and controls. The mean ages of the study subjects in both groups were 25.6 with a SD of \pm 5.5 . The majority of $99(63.5 \%)$ cases were between 20 and 29 years of age. The majority of $208(63.8 \%)$ of the control groups fell between 20 and 29 years of age. More than 151 (96.8\%) cases and 303 (92.9\%) controls were married. Regarding educational status, the majority of 43 (27.6\%) cases and 97 (29.8\%) controls had attended primary education. Eighty-seven (55.6\%) cases were housewives compared to 168 (51.5\%) controls, on which they had a similar duty in their house (Table 1).

Thirty-seven (23.7\%) cases had a family history of chronic hypertension. Regarding the medical illness of participants, the family history of the diabetes mellitus was $6.4 \%$ in cases and $9.2 \%$ in controls. The personnel history of diabetes mellitus was also reported as $5.8 \%$ in cases and $4 \%$ in controls. The history of modern contraceptives use was slightly lower in cases than does in controls, in which it was reported to be $46.9 \%$ in cases compared to $49.1 \%$ in control counterparts. Regarding the body mass index of participants, $92(59.0 \%)$ cases had a normal body mass index (Table 2).

3.2. Obstetric-Related Factors of Participants. Regarding the number of pregnancies, 60 (38.5\%) cases and 133 (40.8\%) controls had more than one child. Sixty-five $(41.7 \%)$ of the cases and $166(50.9 \%)$ of the controls had conceived their pregnancy between two to five years interval (Table 3).

Multivariable analysis revealed that having no child, normal BMI, and a family history of chronic hypertension was found to have a significant statistical association with preeclampsia.

Concerning the body mass index, it was revealed that having normal weight index was found to protect the women from preeclampsia. The odds of developing preeclampsia were decreased by $58 \%$ for women with normal weight compared to their underweight counterparts ( $\mathrm{AOR}=0.42,95 \% \mathrm{CI}: 0.21-0.87)$. In this study, having no child was independently associated with preeclampsia. The odds of developing preeclampsia were 1.62 times higher in women who had no pregnancy interval compared to women with an interpregnancy interval between two and five years $(\mathrm{AOR}=1.62$; 95\% CI: 1.03-2.55). The multivariable analysis also revealed that the risk of developing preeclampsia was 2.4 times higher among women who had close relatives with a history of chronic hypertension $(\mathrm{AOR}=2.42,95 \% \mathrm{CI}: 1.16-5.05)$ (Table 4$)$.

\section{Discussion}

A hospital-based case-control study was conducted with the aim of identifying individual and obstetric factors of preeclampsia. After the multivariable analysis has been adjusted for a singleton pregnancy, it found no pregnancy interval 
TABLE 1: Sociodemographic characteristics of women enrolled for a case-control study conducted among singleton pregnant women attending perinatal care in Omo district hospitals, southern Ethiopia. Individual and family-related characteristics of participants.

\begin{tabular}{|c|c|c|c|c|c|}
\hline \multirow{2}{*}{ Variable } & \multicolumn{2}{|c|}{ Outcome variable } & \multirow{2}{*}{$\mathrm{X}^{2}$} & \multirow{2}{*}{ Crude odds ratio $(95 \% \mathrm{CI})$} & \multirow{2}{*}{$p$ value } \\
\hline & Preeclampsia, $n(\%)$ & Controls, $n(\%)$ & & & \\
\hline \multicolumn{6}{|l|}{ Participant age } \\
\hline$<20$ years & $22(14.1 \%)$ & $36(11.0 \%)$ & 1.56 & 1 (ref) & \\
\hline $20-29$ & $99(63.5 \%)$ & $208(63.8 \%)$ & & $0.78(0.44-1.39)$ & 0.40 \\
\hline $30-34$ & $24(15.4 \%)$ & $51(15.6 \%)$ & & $0.77(0.38-1.58)$ & 0.48 \\
\hline 35 and above & $11(7.1 \%)$ & $31(9.5 \%)$ & & $0.58(0.24-1.38)$ & 0.22 \\
\hline \multicolumn{6}{|l|}{ Residence } \\
\hline Urban & $81(51.9 \%)$ & $178(54.6 \%)$ & 0.30 & $0.90(0.61-1.32)$ & 0.58 \\
\hline Rural & $75(48.1 \%)$ & $148(45.4 \%)$ & & Ref & \\
\hline \multicolumn{6}{|l|}{ Women's occupation } \\
\hline Housewife & $87(55.6 \%)$ & $168(51.5 \%)$ & 3.08 & $1.41(0.57-3.47)$ & 0.46 \\
\hline Merchant & $23(14.7 \%)$ & $47(14.4 \%)$ & & $1.33(0.49-3.61)$ & 0.58 \\
\hline Government employee & $15(9.6 \%)$ & $43(13.2 \%)$ & & $0.95(0.33-2.70)$ & 0.92 \\
\hline Private worker & $8(5.1 \%)$ & $23(7.1 \%)$ & & $0.94(0.28-3.08)$ & 0.92 \\
\hline Students & $16(10.3 \%)$ & $26(8.0 \%)$ & & $1.67(0.58-4.86)$ & 0.35 \\
\hline Others & $7(4.5 \%)$ & $19(5.8 \%)$ & & Ref & \\
\hline \multicolumn{6}{|l|}{ Husband's occupation } \\
\hline Government employee & $45(28.8 \%)$ & $92(28.2 \%)$ & 6.58 & $0.71(0.31-1.66)$ & 0.43 \\
\hline Private employee & $37(23.7 \%)$ & $103(31.6 \%)$ & & $0.52(0.22-1.23)$ & 0.14 \\
\hline Farmer & $55(35.3 \%)$ & $89(27.3 \%)$ & & $0.90(0.39-2.08)$ & 0.80 \\
\hline Merchant & $8(5.1 \%)$ & $26(8.0 \%$ & & $0.45(0.15-1.24)$ & 0.15 \\
\hline Others & $11(7.1 \%)$ & $16(4.9 \%)$ & & Ref & \\
\hline \multicolumn{6}{|l|}{ Marital status } \\
\hline Unmarried & $5(3.2 \%)$ & $23(7.2 \%)$ & 2.59 & Ref & \\
\hline Married & $151(96.8 \%)$ & $303(92.9 \%)$ & & $2.29(0.86-6.06)$ & 0.09 \\
\hline \multicolumn{6}{|l|}{ Educational level } \\
\hline No formal education & $40(25.6 \%)$ & $71(21.8 \%)$ & 2.48 & & \\
\hline Primary level & $43(27.6 \%)$ & $97(29.8 \%)$ & & $0.79(0.46-1.33)$ & 0.37 \\
\hline Secondary level & $37(23.7 \%)$ & $94(28.8 \%)$ & & $0.70(0.41-1.20)$ & 0.20 \\
\hline College and above & $36(23.1 \%)$ & $64(19.6 \%)$ & & $0.99(0.57-1.75)$ & 0.99 \\
\hline
\end{tabular}

and having primary relatives with a history of chronic hypertension as a risk factor, while normal body mass index was a protective factor for preeclampsia. The novel finding in this study was that a weak but significant association exists between normal BMI and preeclampsia in a singleton pregnancy where it would be a marker of nutritional deprivation.

The findings of this study are supported by several studies [23-27]. Levels of physical activity among subjects might also suggest the occurrence of elevated blood pressure in pregnant women, in which the risk of high blood pressure among subjects with high physical activity and normal weight was reduced nearly by half, as a prospective cohort study revealed [23]. Another study also reported that there was a weak but significant negative association between BMI and blood pressure. This might suggest a link between malnutrition and elevated BP [25]. A study from Italy reported that participants with normal weight had a lower prevalence of elevated blood pressure compared with enrollees with overweight [26]. Furthermore, a recent review comparing the US and non-US population indicated that a normal body mass index (BMI) was correlated with a low incidence of hypertension [27]. A multicountry study in Africa and Asia countries including Ethiopia revealed that BMI has a negative or weak association with blood pressure.
The weak but significant linear relationship between BMI and maternal blood pressure in Ethiopia was limited to those women whose BMI includes normal BMI. In this regard, undernutrition $(42.7 \%)$ and the physical activity level may explain the negative association between normal body mass index and increased blood pressure [24]. Eventhough we found a negative association between normal BMI and preeclampsia, undernutrition may be an important factor of elevated blood pressure in the area where it is prevalent. Thus, careful evaluation of the contribution of undernutrition to preeclampsia would be important.

According to this study, women who had no child were independently associated with preeclampsia. This finding is in line with several studies [28-30]. It has been shown that the incidence of preeclampsia was three times higher among women who had no child [28]. Another study conducted in Norwegian women indicated that the odds of developing preeclampsia were increased by 3.6 times among women with no previous childbirth history [31]. Maternal immunity maladaptation is the suggested explanation linked to nulliparity, in which how the maternal immune system reacts to early trophoblastic cells invasion leads to maladaptation of the spiral arterioles [8]. The extent of immunological exposure is the reason for an increased or decreased risk of preeclampsia in subsequent pregnancies [32]. 
TABLE 2: Individual and family-related factors of women enrolled for a case-control study conducted among singleton pregnant women attending perinatal care in Omo district hospitals, southern Ethiopia.

\begin{tabular}{|c|c|c|c|c|c|}
\hline \multirow{2}{*}{ Variable } & \multicolumn{2}{|c|}{ Outcome variable } & \multirow{2}{*}{$X^{2}$} & \multirow{2}{*}{ Crude odds ratio $(95 \% \mathrm{CI})$} & \multirow{2}{*}{$p$ value } \\
\hline & Preeclampsia, $n(\%)$ & Controls, $n(\%)$ & & & \\
\hline \multicolumn{6}{|c|}{ Family history of chronic hypertension } \\
\hline No apparent history & $119(76.3 \%)$ & $276(84.7 \%)$ & 5.73 & 1 (ref) & \\
\hline Primary relatives only & $18(11.5 \%)$ & $20(6.1 \%)$ & & $2.09(1.07-4.09)$ & 0.03 \\
\hline Secondary relatives only & $19(12.2 \%)$ & $30(9.2 \%)$ & & $1.47(0.79-2.71)$ & 0.22 \\
\hline \multicolumn{6}{|c|}{ Family history of diabetes mellitus } \\
\hline Yes & $10(6.4 \%)$ & $30(9.2 \%)$ & 1.08 & $0.68(0.32-1.42)$ & \\
\hline No & $146(93.6 \%)$ & $296(90.8 \%)$ & & Ref & 0.30 \\
\hline \multicolumn{6}{|c|}{ Personnel history of diabetes mellitus } \\
\hline Yes & $9(5.8 \%)$ & $13(4.0 \%)$ & 0.77 & $1.47(0.62-3.53)$ & \\
\hline No & $147(94.2 \%)$ & $313(96.0 \%)$ & & Ref & 0.38 \\
\hline \multicolumn{6}{|l|}{ Maternal asthma } \\
\hline Yes & $11(92.9 \%)$ & $14(4.3 \%)$ & 1.63 & $1.69(0.75-3.82)$ & 0.21 \\
\hline No & $145(7.1 \%)$ & $312(95.7 \%)$ & & Ref & \\
\hline \multicolumn{6}{|l|}{ History of abortion } \\
\hline Yes & $27(17.3 \%)$ & $60(18.4 \%)$ & 0.09 & $0.92(0.56-1.53)$ & 0.77 \\
\hline No & $129(82.7 \%)$ & $266(81.6 \%)$ & & Ref & \\
\hline \multicolumn{6}{|l|}{ Haematologic status } \\
\hline Low haemoglobin & $56(35.9 \%)$ & $106(32.5 \%)$ & 0.54 & $1.16(0.78-1.74)$ & 0.46 \\
\hline Normal haemoglobin & $100(64.1 \%)$ & $220(67.5 \%)$ & & Ref & \\
\hline \multicolumn{6}{|l|}{ Contraceptive use } \\
\hline No contraceptive use & $83(53.2 \%)$ & $166(50.9 \%)$ & 1.83 & Ref & \\
\hline Injectable & $50(32.1 \%)$ & $98(30.1)$ & & $1.02(0.66-1.57)$ & 0.93 \\
\hline Implants & $14(9.0 \%)$ & $43(13.2 \%)$ & & $0.65(0.34-1.26)$ & 0.20 \\
\hline Oral pills & $9(5.8 \%)$ & $19(5.8 \%)$ & & $0.95(0.41-2.19)$ & 0.90 \\
\hline \multicolumn{6}{|l|}{ Body mass index (BMI) } \\
\hline Underweight & $18(11.5 \%)$ & $19(5.8 \%)$ & 8.12 & Ref & \\
\hline Normal & $92(59.0 \%)$ & $215(66.0 \%)$ & & $0.45(0.23-0.90$ & 0.02 \\
\hline Overweight & $39(25.0 \%)$ & $86(26.4 \%)$ & & $0.48(0.23-1.01)$ & 0.05 \\
\hline Obese & $7(4.5 \%)$ & $6(1.8 \%)$ & & $1.23(0.35-4.37)$ & 0.75 \\
\hline
\end{tabular}

TABLE 3: Obstetric-related characteristics of women enrolled for a case-control study on factors of preeclampsia among pregnant women in Omo district hospitals, southern Ethiopia. The identified factors of preeclampsia.

\begin{tabular}{|c|c|c|c|c|c|}
\hline \multirow{2}{*}{ Variable } & \multicolumn{2}{|c|}{ Outcome variable } & \multirow{2}{*}{$X^{2}$} & \multirow{2}{*}{ Crude odds ratio $(95 \% \mathrm{CI})$} & \multirow{2}{*}{$p$ value } \\
\hline & Preeclampsia, $n(\%)$ & Controls, $n(\%)$ & & & \\
\hline \multicolumn{6}{|l|}{ Fetal sex } \\
\hline Male & $87(55.8 \%)$ & $177(54.3 \%)$ & 0.10 & $1.06(0.72-1.56)$ & 0.76 \\
\hline Female & $69(44.2 \%)$ & $149(45.7 \%)$ & & Ref & \\
\hline \multicolumn{6}{|l|}{ Parity } \\
\hline Nulliparous & $58(37.2 \%)$ & $100(30.7 \%)$ & 2.53 & $1.84(0.69-4.86)$ & 0.22 \\
\hline Primiparous & $32(20.5 \%)$ & $74(22.7 \%)$ & & $1.37(0.50-3.75)$ & 0.54 \\
\hline Multiparous & $60(38.5 \%)$ & $133(40.8 \%)$ & & $1.43(0.54-3.76)$ & 0.47 \\
\hline Grandmultiparous & $6(3.8 \%)$ & $19(5.8 \%)$ & & Ref & \\
\hline \multicolumn{6}{|l|}{ Pregnancy interval } \\
\hline No prior childbirth & $59(37.8 \%)$ & $107(32.8 \%)$ & 3.73 & $1.41(0.92-2.16)$ & 0.12 \\
\hline Less than 2 years & $32(20.5 \%)$ & $53(16.3 \%)$ & & $1.54(0.91-2.60)$ & 0.11 \\
\hline Two to five years & $65(41.7 \%)$ & $166(50.9 \%)$ & & Ref & \\
\hline \multicolumn{6}{|c|}{ Pregnancy from new partner } \\
\hline Yes & $33(21.2 \%)$ & $63(19.3 \%)$ & 0.22 & $1.12(0.70-1.80)$ & 0.64 \\
\hline No & $123(78.8 \%)$ & $263(80.7 \%)$ & & Ref & \\
\hline \multicolumn{6}{|l|}{ ANC follow-up status } \\
\hline Yes & $106(67.9 \%)$ & $212(65.0 \%)$ & 0.40 & $1.14(0.76-1.71)$ & \\
\hline No & $50(32.1 \%)$ & $114(35.0 \%)$ & & Ref & 0.53 \\
\hline \multicolumn{6}{|l|}{ Nutritional counselling } \\
\hline Yes & $138(88.5 \%)$ & $304(93.3 \%)$ & 3.2 & $0.56(0.29-1.07)$ & 0.07 \\
\hline No & $18(11.5 \%)$ & $22(6.7 \%)$ & & Ref & \\
\hline
\end{tabular}


TABLE 4: Multivariable output for a case-control study on personnel and obstetric factors of preeclampsia among pregnant women attending hospitals in southern Ethiopia.

\begin{tabular}{|c|c|c|c|c|}
\hline \multirow{2}{*}{ Variable } & \multicolumn{2}{|c|}{ Outcome variable } & \multirow{2}{*}{ Adjusted odds ratio (95\% CI) } & \multirow{2}{*}{$p$ value } \\
\hline & Preeclampsia, $n(\%)$ & Controls, $n(\%)$ & & \\
\hline \multicolumn{5}{|l|}{ Husband's occupation } \\
\hline Government employee & $45(28.8 \%)$ & $92(28.2 \%)$ & $0.64(0.27-1.55)$ & 0.34 \\
\hline Private employee & $37(23.7 \%)$ & $103(31.6 \%)$ & $0.46(0.19-1.12)$ & 0.09 \\
\hline Farmer & $55(35.3 \%)$ & $89(27.3 \%)$ & $0.78(0.33-1.87)$ & 0.58 \\
\hline Merchant & $8(5.1 \%)$ & $26(8.0 \%)$ & $0.32(0.10-1.02)$ & 0.06 \\
\hline Others & $11(7.1 \%)$ & $16(4.9 \%)$ & Ref & \\
\hline \multicolumn{5}{|l|}{ Body mass index (BMI) } \\
\hline Underweight & $18(11.5 \%)$ & $19(5.8 \%)$ & Ref & \\
\hline Normal weight & $92(59.0 \%)$ & $215(66.0 \%)$ & $0.42(0.21-0.87)$ & 0.02 \\
\hline Overweight & $39(25.0 \%)$ & $86(26.4 \%)$ & $0.49(0.23-1.06)$ & 0.07 \\
\hline Obese & $7(4.5 \%)$ & $6(1.8 \%)$ & $1.46(0.39-5.55)$ & 0.58 \\
\hline \multicolumn{5}{|l|}{ Pregnancy interval } \\
\hline No prior childbirth & $59(37.8 \%)$ & $107(32.8 \%)$ & $1.62(1.03-2.55)$ & 0.04 \\
\hline Less than 2 years & $32(20.5 \%)$ & $53(16.3 \%)$ & $1.74(1.00-3.03)$ & 0.05 \\
\hline Two to five years & $65(41.7 \%)$ & $166(50.9 \%)$ & $(1.01-3.03)$ & \\
\hline \multicolumn{5}{|l|}{ Marital status } \\
\hline Unmarried & $5(3.2 \%)$ & $23(7.2 \%)$ & Ref & \\
\hline Married & $151(96.8 \%)$ & $303(92.9 \%)$ & $2.58(0.93-7.17)$ & 0.07 \\
\hline \multicolumn{5}{|c|}{ Family history of diabetes mellitus } \\
\hline Yes & $10(6.4 \%)$ & $30(9.2 \%)$ & $2.31(0.91-5.84)$ & 0.08 \\
\hline No & $146(93.6)$ & $296(90.8)$ & Ref & \\
\hline \multicolumn{5}{|c|}{ Family history of chronic hypertension } \\
\hline No history & $119(76.3 \%)$ & $276(84.7 \%)$ & Ref & \\
\hline Primary relatives & $18(11.5 \%)$ & $20(6.1 \%)$ & $2.42(1.16-5.05)$ & 0.02 \\
\hline Secondary relatives & $19(12.2 \%)$ & $30(9.2 \%)$ & $1.32(0.68-2.55)$ & 0.42 \\
\hline \multicolumn{5}{|c|}{ Personnel history of diabetes mellitus } \\
\hline Yes & $9(5.8 \%)$ & $13(4.0 \%)$ & $0.35(0.12-1.01)$ & 0.05 \\
\hline No & $147(94.2 \%)$ & $313(96.0 \%)$ & Ref & \\
\hline
\end{tabular}

Concerning to the medical history of participants, the family history of chronic hypertension with primary relatives was a statistically significant factor that increases the risk of preeclampsia. This finding is consistent with studies conducted in Dessie [22], Addis Ababa [33], Gedio [34], India and Kenya [17, 35], and Pakistan [36]. This might be because of a behavioural or genetic-related factor that contributes to the physiologic susceptibility of preeclampsia.

4.1. Limitations of the Study. Using a case-control study design and enrollment of a representative sample is the strength of this study. Due to the retrospective nature of the study, recall bias can be the challenge. The facility-based study limits the finding to be limited to women attending perinatal care in a hospital. Despite a wide range of geographic area, interested researchers may consider as a basis for future work.

\section{Conclusions}

In light of the findings, it can be concluded that having primary relatives who had a history of chronic hypertension and no interpregnancy interval were independent risk factors, whereas having normal body mass index protects women from developing preeclampsia. Therefore, it is recommended that planning the maternal health program at the district level should incorporate preventive and control strategies focusing on the risk factors and women should be advised to keep the normal bodyweight index with regular activity and adequate nutrition.

\section{Declarations}

We, the undersigned, agree to accept responsibility for the scientific, ethical, and technical conduct of the research project mentioned and for the provision of required progress reports and financial settlements as per the terms and conditions of the university if the grant is awarded as the result of this application.

\section{Abbreviations}

ANC: Antenatal care

AOR: Adjusted odds ratio

BMI: Body mass index

COD: Crude odds ratio

CI: Confidence interval

WHO: World Health Organisation.

\section{Data Availability}

Datasets used in this study are available from the corresponding author upon reasonable request. 


\section{Ethical Approval}

Ethical approval was obtained from the Ethical Review Committee of the College of Medicine and Health Sciences, Arbaminch University. An official letter of cooperation was written to each hospital to get permission. Formal written consent was also obtained from the study participants. Similarly, the participants were informed about the purpose of the study, privacy, and confidentiality issues. Participation was involved only if she said so, and she had the right to be off anytime she wants to. If she did, the study assures that she had nothing to lose from the service she expected to receive. All information gained during data collection was kept confidential, and any personal identification was not recorded on the questionnaire.

\section{Conflicts of Interest}

The authors declare that they have no conflicts of interest.

\section{Authors' Contributions}

KF involved in conception, planning, carrying out data collection, analyzing and writing up of the work, and manuscript development.

\section{References}

[1] E. A. Steegers, P. Von Dadelszen, J. J. Duvekot, and R. Pijnenborg, "Pre-eclampsia," The Lancet, vol. 376, no. 9741, pp. 631-644, 2010.

[2] K. O. Osungbade and O. K. Ige, "Public health perspectives of preeclampsia in developing countries: implication for health system strengthening," Journal of Pregnancy, vol. 2011, 2011.

[3] L. Say, D. Chou, A. Gemmill et al., "Global causes of maternal death: a WHO systematic analysis," The Lancet Global Health, vol. 2, no. 6, pp. e323-e333, 2014.

[4] W. Mekonnen and A. Gebremariam, "Causes of maternal death in Ethiopia between 1990 and 2016: a systematic review with meta-analysis," Ethiopian Journal of Health Development, vol. 32, no. 4, 2018.

[5] H. Garomssa and A. Dwivedi, "Maternal mortality in Ambo Hospital: a five-year retrospective review," Ethiopian Journal of Reproductive Health, vol. 2, no. 1, 2008.

[6] K. O. I. O. Osungbade, "Public health perspectives of preeclampsia in developing countries: implication for health system strengthening," Journal of Pregnancy, vol. 20116 pages, 2011.

[7] R. V.-J. K. Lamminpää, M. Gissler, and S. Heinonen, "Preeclampsia complicated by advanced maternal age: a registrybased study on primiparous women in Finland 1997-2008," BMC Pregnancy Childbirth, vol. 12, no. 1, 2012.

[8] F. A. F. Kahnamouei-Adam and S. Hamidimoghaddam, "Prevalence of pre-eclampsia and eclampsia risk factors among pregnant women, 2011-2013," International Journal of Advances in Medicine, vol. 2, no. 2, pp. 128-132, 2015.

[9] K. Bibbins-Domingo, D. C. Grossman, S. J. Curry et al., "Screening for preeclampsia: US preventive services task force recommendation statement," JAMA, vol. 317 , no. 16, pp. 1661-1667, 2017.

[10] A. NO, Factors Contributing to Adverse Outcomes of Preeclampsia Among Pregnant Women Attending Antenatal
Clinics in Kibera Slums, Doctoral dissertation, University of Nairobi, Kenya, Nairobi, Kenya, 2012.

[11] E. N. E. Tesfa, S. T. Gizaw, Y. Zenebe et al., "Prevalence and determinants of hypertensive disorders of pregnancy in Ethiopia: a systematic review and meta-analysis," PloS One, vol. 15 , no. $9,2020$.

[12] V. C. D. Filippi, C. Ronsmans, W. Graham, and L. Say, Levels and Causes of Maternal Mortality and Morbidity, https://elibrary. worldbank.org/doi/abs/10.1596/978-1-4648-0348-2_ch3, 2016.

[13] A. A. Maternal, "Mortality trend in Ethiopia," Ethiopian Journal of Health Development, vol. 24, no. 1, 2010.

[14] World Health Organization, WHO Recommendations for the Prevention and Treatment of Pre-eclampsia and Eclampsia, WHO, Geneva, Switzerland, 2011.

[15] S. Currie, J. De Graft-Johnson, R. Galloway, C. Sheehan, and J. Smith, Interventions for Impact on Essential Obstetric and Newborn Care, Asia Regional Meeting [meeting report, Dhaka, Bangladesh, 2012.

[16] "A conceptual framework for the revision of the ICD-10 classification of mental and behavioural disorders," World Psychiatry, vol. 10, no. 2, pp. 86-92, 2011.

[17] G. G. Logan, P. K. Njoroge, L. O. Nyabola, and M. M. Mweu, "Determinants of preeclampsia and eclampsia among women delivering in county hospitals in Nairobi, Kenya," F1000Research, vol. 9, no. 192, p. 192, 2020.

[18] N. Skursky, E. Sedlander, and K. Barboza, "Abstracts from the 38 th annual meeting of the society of general internal medicine," Journal of General Internal Medicine, vol. 30, no. 2, pp. 45-551, 2015.

[19] G. K. W. Sutapa Agrawal, "Prevalence and risk factors for preeclampsia in Indian women: a national cross sectional study," Journal of Women Health Issues and Care, 2014.

[20] P. M. Tebeu, P. Foumane, R. Mbu, G. Fosso, P. T. Biyaga, and J. N. Fomulu, "Risk factors for hypertensive disorders in pregnancy: a report from the maroua regional hospital, Cameroon," Journal of Reproduction \& Infertility, vol. 12, no. 3, pp. 227-234, 2011.

[21] Y. Yogev, M. Nir, R. Bardin et al., "Pregnancy outcome at extremely advanced maternal age," American Journal of Obstetrics and Gynecology, vol. 203, pp. 558-e1, 2010.

[22] G. A. Tessema, A. Tekeste, and A. A. Tadesse, "Preeclampsia and associated factors among pregnant women attending antenatal care in Dessie referral hospital, Northeast Ethiopia: a hospital-based study," BMC Pregnancy and Childbirth, vol. 15, p. 73, 2015.

[23] G. Hu, N. C. Barengo, J. Tuomilehto, T. A. Lakka, A. Nissinen, and P. Jousilahti, "Relationship of physical activity and body mass index to the risk of hypertension: a prospective study in Finland," Hypertension, vol. 43, no. 1, pp. 25-30, 2004.

[24] F. Tesfaye, N. G. Nawi, H. Van Minh et al., "Association between body mass index and blood pressure across three populations in Africa and Asia," Journal of Human Hypertension, vol. 21, no. 1, pp. 28-37, 2007.

[25] A. K. Salahudeen, E. H. Fleischmann, J. D. Bower, and J. E. Hall, "Underweight rather than overweight is associated with higher prevalence of hypertension: BP vs BMI in haemodialysis population," Nephrology Dialysis Transplantation, vol. 19, no. 2, pp. 427-432, 2004.

[26] F. Landi, R. Calvani, A. Picca et al., "Body mass index is strongly associated with hypertension: results from the Longevity Check-up 7+ Study," Nutrients, vol. 10, no. 12, p. 1976, 2018.

[27] A. Younus, E. C. Aneni, and E. S. Spatz, "A systematic review of the prevalence and outcomes of ideal cardiovascular health 
in US and non-US populations," in Mayo Clinic Proceedings, et al. vol. 91, no. 5, , pp. 649-670, Elsevier, 2016.

[28] Z.-C. Luo, N. An, H.-R. Xu, A. Larante, F. Audibert, and W. D. Fraser, "The effects and mechanisms of primiparity on the risk of pre-eclampsia: a systematic review," Paediatric and Perinatal Epidemiology, vol. 21, no. s1, pp. 36-45, 2007.

[29] J. Wandabwa, P. Doyle, P. Kiondo, O. Campbell, N. Maconichie, and G. Welishe, "Risk factors for severe preeclampsia and eclampsia in Mulago Hospital, Kampala, Uganda," East African Medical Journal, vol. 87, no. 10, p. 415, 2010.

[30] G. Cormick, A. P. Betrán, A. Ciapponi, D. R. Hall, and G. J. Hofmeyr, "Inter-pregnancy interval and risk of recurrent pre-eclampsia: systematic review and meta-analysis," Reproductive Health, vol. 13, no. 1, pp. 1-10, 2016.

[31] R. A. Ødegård, L. J. Vatten, S. T. Nilsen, K. A. Salvesen, and R. Austgulen, "Risk factors and clinical manifestations of preeclampsia," BJOG: An International Journal of Obstetrics and Gynaecology, vol. 107, no. 11, pp. 1410-1416, 2000.

[32] D.-K. Li and S. Wi, "Changing paternity and the risk of preeclampsia/eclampsia in the subsequent pregnancy," American Journal of Epidemiology, vol. 151, no. 1, pp. 57-62, 2000.

[33] T. Grum, A. Seifu, M. Abay, T. Angesom, and L. Tsegay, "Determinants of pre-eclampsia/Eclampsia among women attending delivery Services in Selected Public Hospitals of Addis Ababa, Ethiopia: a case-control study," BMC Pregnancy and Childbirth, vol. 17, no. 1, p. 307, 2017.

[34] M. Mareg, A. Molla, S. Dires, Z. Berhanu Mamo, and B. Hagos, "Determinants of preeclampsia among pregnant mothers attending antenatal care (ANC) and delivery service in gedeo zone, southern Ethiopia: case control-study," International Journal of Women's Health, vol. 12, p. 567, 2020.

[35] K. S. Ganesh, B. Unnikrishnan, K. Nagaraj, and S. Jayaram, "Determinants of pre-eclampsia: a case-control study in a district hospital in South India," Indian Journal of Community Medicine: Official Publication of Indian Association of Preventive \& Social Medicine, vol. 35, no. 4, p. 502, 2010.

[36] U. Shamsi, J. Hatcher, A. Shamsi, N. Zuberi, Z. Qadri, and S. Saleem, "A multicentre matched case-control study of risk factors for preeclampsia in healthy women in Pakistan," BMC Women's Health, vol. 10, no. 1, p. 14, 2010. 